\title{
Thermochemical Formation of Polybrominated Dibenzo-p-Dioxins and Dibenzofurans Mediated by Secondary Copper Smelter Fly Ash, and Implications for Emission Reduction
}

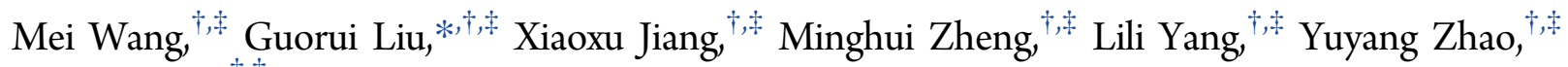 \\ and Rong Jin ${ }^{\dagger,+}$ \\ ${ }^{\dagger}$ State Key Laboratory of Environmental Chemistry and Ecotoxicology, Research Center for Eco-Environmental Sciences, Chinese \\ Academy of Sciences, P.O. Box 2871, Beijing 100085, China \\ ${ }^{\ddagger}$ University of Chinese Academy of Sciences, Beijing 100049, China
}

Supporting Information

\begin{abstract}
Heterogeneous reactions mediated by fly ash are important to polychlorinated dibenzo- $p$-dioxin and dibenzofuran (PCDD/Fs) formation. However, the formation of polybrominated dibenzo-p-dioxins and dibenzofurans (PBDD/Fs) through heterogeneous reactions is not yet well understood. Experiments were performed to investigate the thermochemical formation of $\mathrm{PBDD} / \mathrm{Fs}$ at $150-450{ }^{\circ} \mathrm{C}$ through heterogeneous reactions on fly ash from a secondary copper smelter. The maximum PBDD/ $\mathrm{F}$ concentration was 325 times higher than the initial PBDD/F concentration in the fly ash. The PBDD/F concentration after the experiment at $150{ }^{\circ} \mathrm{C}$ was five times higher than the initial concentration. $\mathrm{PBDD} / \mathrm{Fs}$ have not previously been found to form at such a low temperature. Secondary-copper-smelter fly ash clearly promoted $\mathrm{PBDD} / \mathrm{F}$ formation, and this conclusion was supported by the low activation energies that were found in Arrhenius's law calculations. Thermochemical formation of PBDD/Fs mediated by fly ash deposited in industrial facilities could explain "memory effects" that have been found for PCDD/ Fs and similar compounds released from industrial facilities. Abundant polybrominated diphenyl ethers (PBDEs) that were formed through fly ash-mediated reactions could be important precursors for PBDD/Fs also formed through fly ash-mediated reactions. The amounts of PBDEs that formed through fly ash-mediated reactions suggested that secondary copper smelters could be important sources of reformed PBDEs.

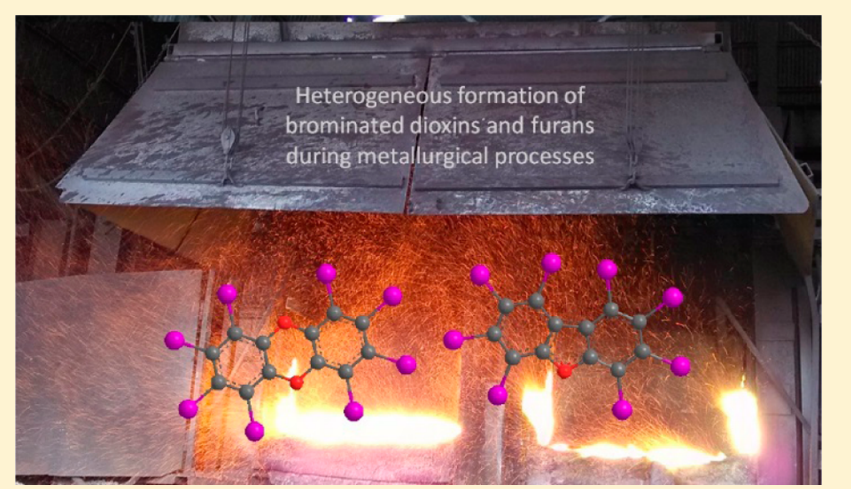

\section{INTRODUCTION}

Heterogeneous reactions on fly ash are widely recognized as being the dominant mechanisms through which polychlorinated dibenzo- $p$-dioxins and dibenzofurans (PCDD/Fs) form during industrial thermal processes. These reactions can occur because carbon-containing residues and catalytic metal particles are abundant in fly ash. ${ }^{1-4}$ Copper compounds are some of the most efficient catalysts of the formation of PCDD/Fs. ${ }^{1,5-8}$

The catalysis of the formation of $\mathrm{PCDD} / \mathrm{Fs}$ and other chlorinated organic contaminants by copper compounds (copper oxides and copper chlorides) under different combustion conditions has been investigated in numerous studies. ${ }^{4,6,9,10}$ Olie et al. reviewed the catalysis of PCDD/F formation by several metals during the incineration of municipal waste, and they found that copper has the strongest catalytic effect. ${ }^{11}$ Stieglitz et al. found that copper(II) ions catalyze reactions on the surfaces of carbon particles in the presence of oxygen, promoting the oxidation of the carbon to $\mathrm{CO}_{2}$ and the formation of chlorinated aromatic compounds. ${ }^{12}$ Nganai et al. investigated the formation of PCDD/Fs through pyrolysis mediated by copper oxide, and they found that divalent copper oxides increased the $\mathrm{PCDD} / \mathrm{F}$ yield to a remarkable extent. ${ }^{7}$ The studies mentioned above showed that copper compounds are effective catalysts for the formation of $\mathrm{PCDD} / \mathrm{Fs}$ during waste incineration processes.

Polybrominated dibenzo-p-dioxins and dibenzofurans (PBDD/Fs) are the brominated analogs of PCDD/Fs, and are also toxic. ${ }^{13} \mathrm{PBDD} / \mathrm{Fs}$ have recently attracted much attention because higher $\mathrm{PBDD} / \mathrm{F}$ toxic equivalents (TEQs) than PCDD/F TEQs have been found in some environmental matrices. $^{14,15}$ Controlling $\mathrm{PBDD} / \mathrm{F}$ emissions should be prioritized so that the amounts of $\mathrm{PBDD} / \mathrm{Fs}$ present in the environment and to which humans are exposed will decrease. $\mathrm{PBDD} / \mathrm{Fs}$ and PCDD/Fs have similar sources, including waste incinerators, secondary nonferrous smelting processes, and iron

Received: April 28, 2016

Revised: June 17, 2016

Accepted: June 27, 2016

Published: June 27, 2016 
and steel making processes. Secondary copper smelting ( $\mathrm{SCu}$ ) processes have been found to be important sources of PBDD/ Fs, and PBDD/Fs have been found at higher concentrations in stack gases produced during $\mathrm{SCu}$ processes $\left(2.5 \mathrm{ng} \mathrm{Nm}^{3-}\right)$ than in stack gases produced during the incineration of waste $(0.025$ ng $\mathrm{Nm}^{3-}$ ), steelmaking using electric arc furnaces (1.5 ng $\mathrm{Nm}^{3-}$ ), and other processes. ${ }^{16,17}$

The underlying reason for PBDD/F emissions during $\mathrm{SCu}$ processes being higher than emissions during other processes has not yet been determined. Copper compounds are found at much higher contents in $\mathrm{SCu}$ systems than in waste incinerators and other industrial systems. ${ }^{18}$ The raw materials (recycled metal wire) used in secondary copper smelters normally contain plastic and cable residues that contain polybrominated diphenyl ethers (PBDEs) or other brominated flame retardants (BFRs). These BFR residues are widely recognized as being important sources of organic bromine for the formation of PBDD/Fs. Metal bromides in fly ash could also act as sources of bromine for the formation of PBDD/F, as has been reported previously. ${ }^{19,20}$ The large amounts of copper compounds present during $\mathrm{SCu}$ processes may catalyze thermochemical reactions between bromine (inorganic or organically bound) and carbon in organic material in scrap metal, allowing $\mathrm{PBDD} / \mathrm{Fs}$ to form. Heterogeneous $\mathrm{PBDD} / \mathrm{F}$ formation reactions mediated by fly ash with a high copper compound content could contribute to larger amounts of $\mathrm{PBDD} / \mathrm{Fs}$ being emitted during $\mathrm{SCu}$ processes than during other processes. However, no attempt has yet been made to quantitatively evaluate the potential for $\mathrm{PBDD} / \mathrm{Fs}$ forming through heterogeneous reactions mediated by real fly ash from $\mathrm{SCu}$ processes.

In this study, thermochemical experiments were performed to allow the potential for the formation of $\mathrm{PBDD} / \mathrm{Fs}$ mediated by real fly ash from a SCu process to be quantified. The primary objective of the study was to gain, for the first time, insights into the extent to which real fly ash promotes the formation of PBDD/Fs during SCu processes. The results of this study will help characterize the role fly ash plays in the formation of $\mathrm{PBDD} / \mathrm{Fs}$, and this will help in the development of techniques for controlling PBDD/F emissions.

\section{EXPERIMENTAL SECTION}

Thermochemical Experiment Design. The fly ash that was used as a matrix for the formation of PBDD/Fs through heterogeneous reactions was collected from a bag filter in a typical SCu plant. This fly ash was used to simulate, as closely as possible, the active surfaces of fly ash produced during thermochemical processes. ${ }^{3}$ The SCu fly ash had a particularly high copper concentration, $260 \pm 2.0 \mathrm{mg} / \mathrm{g}$, which was determined using an inductively coupled plasma-optical emission spectrometer. ${ }^{21,22}$ The fly ash had a bromine content of $0.3 \%$, determined using a scanning electron microscope with energy dispersive X-ray analysis. ${ }^{22}$ The porosity and specific surface area of the fly ash were determined using a BrunauerEmmett-Teller analytical system. ${ }^{22}$ The specific surface area of the $\mathrm{SCu}$ fly ash was $3.5 \mathrm{~m}^{2} \mathrm{~g}^{-1}$ (Supporting Information (SI) Table S3). The high surface area of the SCu fly ash could have allowed the surface and external reactants involved in reactions to easily come into contact with each other.

The thermochemical experiments were performed in a temperature-controlled quartz horizontal laboratory furnace that had an internal diameter of $45 \mathrm{~mm}$ and was $600 \mathrm{~mm}$ long. Synthetic air was passed through the furnace at a constant flow rate of $50 \mathrm{~mL} / \mathrm{min}$ to simulate the conditions in an open $\mathrm{SCu}$ smelter system. A 200-mg sample of SCu fly ash in a uniform layer in a porcelain boat was placed in the furnace, then the furnace was heated to the desired temperature. Experiments were performed at $150,200,250,350$, and $450{ }^{\circ} \mathrm{C}$. The set temperature in each experiment was held for between 10 and $240 \mathrm{~min}$. The experiments were performed to allow the potential for PBDD/Fs to be formed at different temperatures to be quantified. The gas phase reaction products that were evolved in an experiment were trapped by passing the gas leaving the furnace through two ice-cooled impingers containing toluene. After each experiment, the quartz tube and the fittings and connecting tubes were rinsed three times with toluene to recover any products that had been deposited on the surfaces. The gaseous products of the thermochemical experiments were therefore in two solutions, the cleaning solution (the toluene used to rinse the apparatus) and the absorption solution (the toluene in the impingers). The toluene solutions and the solid residue that remained after each thermochemical experiment had been completed were stored at around $4{ }^{\circ} \mathrm{C}$ until they were analyzed.

Analytical Procedure. The PBDD/F congeners of interest were identified and quantified using isotope-dilution highresolution gas chromatography (HRGC) combined with highresolution mass spectrometry (HRMS). PBDEs, which could act as $\mathrm{PBDD} / \mathrm{F}$ precursors, were also determined using isotopedilution HRGC/HRMS. The analytical technique and the methods used have previously been described in detail. ${ }^{17,23}$ Briefly, each solid residue sample was spiked with known amounts of ${ }^{13} \mathrm{C}_{12}$-labeled $\mathrm{PBDD} / \mathrm{F}$ and $\mathrm{PBDE}$ internal standards (EDF-5408 and EO-5403; Cambridge Isotope Laboratories, Andover, MA, USA). The sample was then digested in hydrochloric acid, filtered, rinsed with distilled water, dried, and Soxhlet extracted with $250 \mathrm{~mL}$ of toluene for about $24 \mathrm{~h}$. Each gas phase sample (i.e., each cleaning solution and each absorption solution) was spiked with known amounts of the ${ }^{13} \mathrm{C}_{12}$-labeled PBDD/F and PBDE internal standards. Each extract was evaporated to a small volume using a rotary evaporator, then subjected to a series of cleanup steps, including passing the extract through a multilayer silica gel column and a basic alumina column. After the cleanup steps had been completed, the PBDD/Fs and PBDEs were separated by passing the extract through an activated carbon column, which was eluted with $80 \mathrm{~mL}$ of dichloromethane/hexane (5/ $95, \mathrm{v} / \mathrm{v}$ ) to elute the PBDEs and then $250 \mathrm{~mL}$ of toluene to elute the PBDD/Fs. Each fraction was evaporated to about 20 $\mu \mathrm{L}$ using a rotary evaporator and then under a gentle stream of $\mathrm{N}_{2}$. A ${ }^{13} \mathrm{C}_{12}$-labeled PBDD/F injection standard (EDF-5409; Cambridge Isotope Laboratories) was added to the PBDD/F fraction and a ${ }^{13} \mathrm{C}_{12}$-labeled $\mathrm{PBDE}$ injection standard (EO5404; Cambridge Isotope Laboratories) was added to the PBDE fraction before the fractions were analyzed by HRGC/ HRMS. The injection standards were used to allow the recoveries of the internal standards to be calculated.

The HRGC/HRMS instrument was a Trace GC Ultra coupled to a double focusing mass spectrometer with an electron impact ion source (Thermo Fisher Scientific, Waltham, MA). A DB-5MS fused-silica column that was $15 \mathrm{~m}$ long (with a $0.25 \mathrm{~mm}$ i.d. and a $0.10-\mu \mathrm{m}$ film; Agilent Technologies, Santa Clara, CA) was used to separate the PBDD/Fs and decabromodiphenyl ether, using the splitless/surge injection technique (using an injection port temperature of $280^{\circ} \mathrm{C}$ and a glass transfer line temperature of $280^{\circ} \mathrm{C}$ ). A DB-5MS fused- 

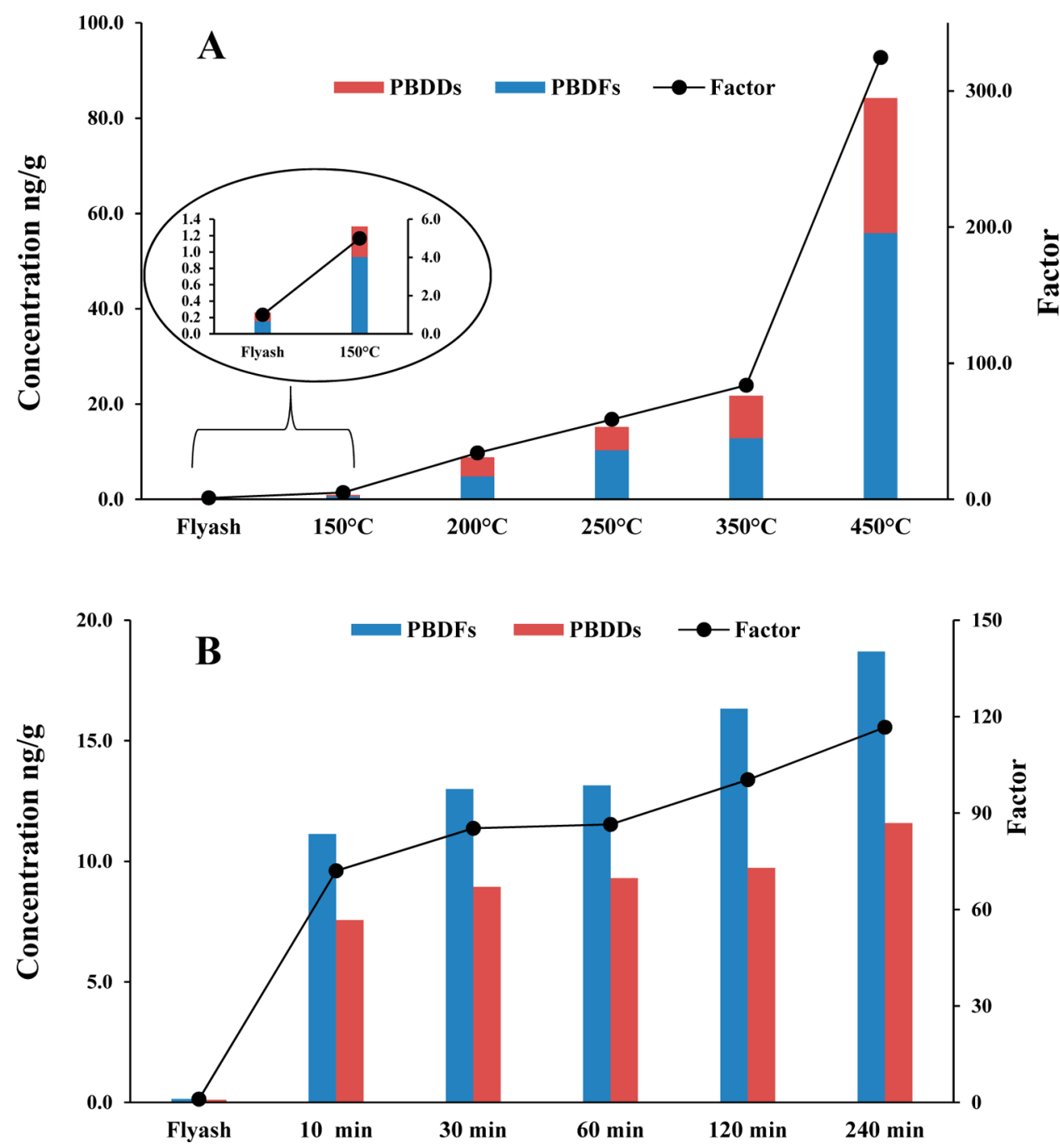

Figure 1. Polybrominated dibenzo-p-dioxin (PBDD) and polybrominated dibenzofuran (PBDF) concentrations (bars and left $y$-axis) and the number of times higher than the concentration in the original fly ash the concentration was (factor; points and right $y$-axis) after the experiments (A) at different temperatures and (B) for different periods of time.

silica column that was $30 \mathrm{~m}$ long (with a $0.25 \mathrm{~mm}$ i.d. and a $0.10-\mu \mathrm{m}$ film; Agilent Technologies) was used to separate the mono- to nona-brominated PBDE congeners (using an injection port temperature of $300{ }^{\circ} \mathrm{C}$ and a glass transfer line temperature of $280^{\circ} \mathrm{C}$ ). The HRMS instrument was operated at a resolution of approximately 10000 , in selected ion monitoring mode, and with an electron energy of $45 \mathrm{eV}$.

Quality Assurance and Quality Control. The reproducibility of the experimental runs was evaluated. The relative standard deviations of the $\mathrm{PBDD} / \mathrm{F}$ concentrations in the samples produced in duplicate runs were $1 \%-19 \%$, indicating that the experimental system and analytical procedure gave an acceptable level of reproducibility. Experimental blanks were produced in thermochemical experiments using a porcelain boat containing no SCu fly ash. A few of the target compounds, including octabromodibenzo- $p$-dioxin (OBDD) and octabromodibenzofuran (OBDF) were detected in the experimental blanks, but the concentrations were less than $0.1 \%$ of the concentrations in the samples produced in the experiments using $\mathrm{SCu}$ fly ash.

Three quality-control criteria were used to identify a target compound: (a) the HRGC retention time had to match the retention time of the corresponding ${ }^{13} \mathrm{C}_{12}$-labeled standard compound; (b) the signal-to-noise ratio had to be $>3$; and (c) the quantification to qualification ion ratio had to be within $\pm 15 \%$ of the theoretical value. The recoveries of the ${ }^{13} \mathrm{C}_{12}$ labeled tetra- to hepta-brominated $\mathrm{PBDD} / \mathrm{F}$ internal standards were $23-128 \%$, and the recoveries of the ${ }^{13} \mathrm{C}_{12}$-labeled OBDD and OBDF internal standards were $20 \%-65 \%$ (SI Table S1). The recoveries of the ${ }^{13} \mathrm{C}_{12}$-labeled PBDE internal standards were $43-124 \%$ (SI Table S2). The isotope dilution HRGC/ HRMS method therefore gave satisfactory recoveries of the PBDD/Fs and PBDEs.

\section{RESULTS AND DISCUSSION}

Potential for PBDD/Fs Forming through Thermochemical Reactions Mediated by SCu Fly Ash. The products of the thermochemical reactions that took place in each experiment were present in the solid residue and the gas phase (captured by the impingers or in the cleaning solution). The relative amounts of the PBDD/Fs that were produced at different temperatures in the solid residue and gas phase samples are shown in SI Figure S1. The PBDD/Fs formed at $150{ }^{\circ} \mathrm{C}$ were mainly (64\% of the total amount) found in the solid residue. Larger amounts of the $\mathrm{PBDD} / \mathrm{Fs}$ formed during the experiments would have been transferred from the solid 

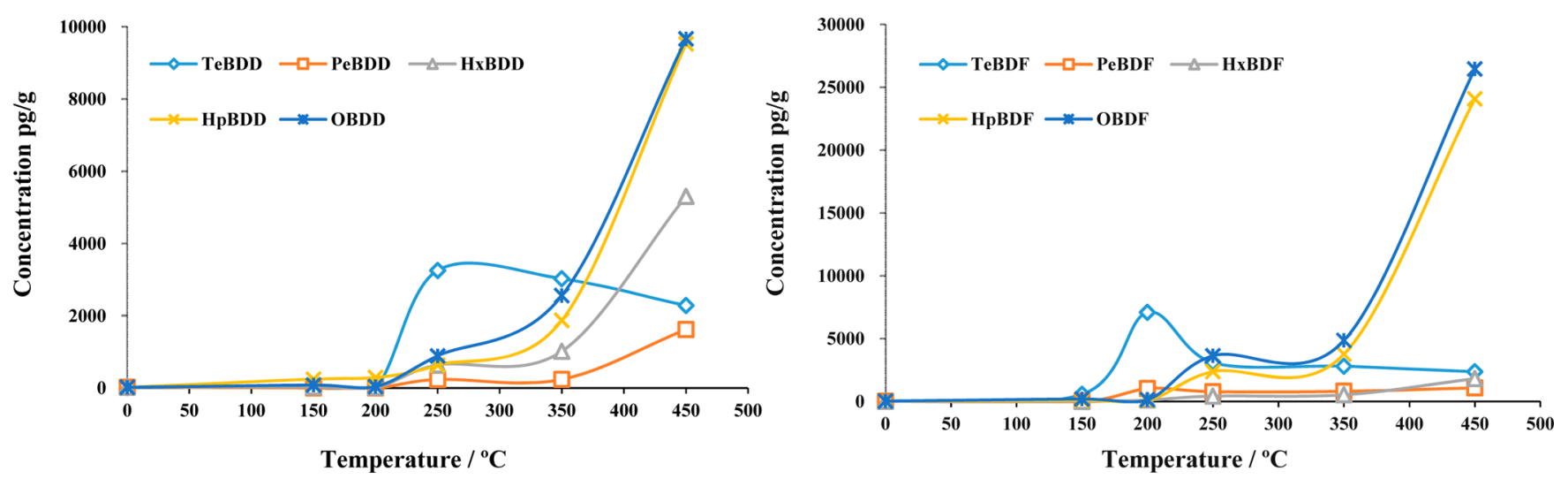

Figure 2. Polybrominated dibenzo-p-dioxin (on the left) and dibenzofuran (on the right) homologue profiles in the original fly ash and after the thermochemical reaction experiments at different temperatures had been performed (BDD $=$ bromodibenzo- $p$-dioxin, BDF $=$ bromodibenzofuran, $\mathrm{Te}=$ tetra, $\mathrm{Pe}=$ penta, $\mathrm{Hx}=$ hexa, $\mathrm{Hp}=$ hepta, $\mathrm{O}=$ octa).

matrix to the gas phase at higher temperatures. It can be seen from SI Figure S1 that the PBDD/Fs formed were predominantly found in the gas phase at $200-450{ }^{\circ} \mathrm{C}(87 \%$ of the total at $200{ }^{\circ} \mathrm{C}, 95 \%$ at $250{ }^{\circ} \mathrm{C}$, and $>99 \%$ at $350-450$ $\left.{ }^{\circ} \mathrm{C}\right)$. This indicates that increasing the temperature increased the proportion of the $\mathrm{PBDD} / \mathrm{Fs}$ formed that entered the gas phase. The sum of the PBDD/F concentrations found in the two phases (solid residue and gas phase) in each test were used in the subsequent assessments of the formation of PBDD/Fs.

The promotion of the formation of PBDD/Fs by $\mathrm{SCu}$ fly ash during the thermochemical experiments at $150-450{ }^{\circ} \mathrm{C}$ for between 10 and $240 \mathrm{~min}$ was evaluated. The PBDD/F concentrations in the $\mathrm{SCu}$ fly ash after the experiments at different temperatures and for different periods of time had been performed are shown in Figure 1. The PBDD to PBDF ratios were in the range $0.4-0.8$, indicating that larger amounts of PBDFs than PBDDs were formed in the experiments. The influence of the temperature on the formation of PBDD/Fs was assessed by performing $30 \mathrm{~min}$ experiments at 150, 200, 250, 350 , and $450{ }^{\circ} \mathrm{C}$. The results of these experiments are shown in Figure 1A.

It is widely accepted that unintentionally produced persistent organic pollutants (POPs) can be formed at between 250 and $450{ }^{\circ} \mathrm{C}^{24-26}$ but that temperatures below $250^{\circ} \mathrm{C}$ do not favor the unintentional formation of POPs. However, it is not yet clear whether PBDD/Fs can form below $250{ }^{\circ} \mathrm{C}$. It can be seen from Figure 1 that the $\mathrm{PBDD} / \mathrm{F}$ concentration after the experiment at $200{ }^{\circ} \mathrm{C}$ was $8.8 \mathrm{ng} / \mathrm{g}$, which was about 34 times higher than the initial PBDD/F concentration in the $\mathrm{SCu}$ fly ash $(0.26 \mathrm{ng} / \mathrm{g})$. The $\mathrm{PBDD} / \mathrm{F}$ concentration after the experiment at $150{ }^{\circ} \mathrm{C}$ was $1.3 \mathrm{ng} / \mathrm{g}$, about five times higher than the initial concentration. $\mathrm{PBDD} / \mathrm{Fs}$ have not previously been found to form at temperatures as low as $150{ }^{\circ} \mathrm{C}$. These results indicate that $\mathrm{SCu}$ fly ash clearly promoted the formation of $\mathrm{PBDD} / \mathrm{Fs}$ even at low temperatures.

Extremely high PBDD/F concentrations (58-325 times higher than the initial PBDD/F concentrations in the $\mathrm{SCu}$ fly ash) were found after the experiments at $250-450{ }^{\circ} \mathrm{C}$. The highest concentration (325 times higher than the initial PBDD/ $\mathrm{F}$ concentration) was found after a $30 \mathrm{~min}$ experiment at 450 ${ }^{\circ} \mathrm{C}$. These results indicate that the $\mathrm{SCu}$ fly ash strongly promoted the formation of PBDD/Fs at $250-450{ }^{\circ} \mathrm{C}$.

The PBDD/F concentrations found after experiments lasting different lengths of time are shown in Figure $1 \mathrm{~B}$. Thermochemical experiments were performed at $350{ }^{\circ} \mathrm{C}$ for
$10,30,60,120$, and $240 \mathrm{~min}$. The PBDD/F concentration had increased dramatically, to 72 times higher than the concentration in the original SCu fly ash, after a reaction time of 10 min. It can be seen from Figure $1 \mathrm{~B}$ that the $\mathrm{PBDD} / \mathrm{F}$ concentration increased slightly as the reaction time increased. The PBDD/F concentration increased from $18.7 \mathrm{ng} / \mathrm{g}$ after 10 $\mathrm{min}$ to $30.3 \mathrm{ng} / \mathrm{g}$ after $240 \mathrm{~min}$.

Toxic equivalent factors (TEFs) for PBDD/Fs and mixed brominated/chlorinated dibenzo- $p$-dioxins and dibenzofurans relative to 2,3,7,8-tetrachlorodibenzo-p-dioxin (the TEF of which was assigned a value of 1.0) have recently been determined. These TEFs allow the TEQs of PBDD/Fs and mixed brominated/chlorinated dibenzo- $p$-dioxins and dibenzofurans in environmental matrices to be estimated. ${ }^{13,27-29}$ The $\mathrm{PBDD} / \mathrm{F}$ TEQ concentrations were calculated using TEF values (shown in SI Table S4) determined by Behnisch et al. ${ }^{13}$ and the concentrations of the individual PBDD/F congeners. The TEQ concentrations of $\mathrm{PBDD} / \mathrm{Fs}$ formed during the thermochemical reactions were $0.18-4.33 \mathrm{ng} \mathrm{TEQ} / \mathrm{g}$ (as shown in SI Table S5), and the maximum TEQ value was about 144 times higher than the initial PBDD/F TEQ concentration in the $\mathrm{SCu}$ fly ash (0.03 ng TEQ/g). Fly ash is normally recycled by adding it to the raw materials during the feedingfusion stages, or fly ash is simply thermally treated during the smelting process. Taking into consideration the increases in the $\mathrm{PBDD} / \mathrm{F}$ TEQ concentrations during the thermochemical reactions, fly ash needs to be disposed of safely rather than simply being recycled by adding it to the raw materials or being thermally treated in $\mathrm{SCu}$ and other metallurgical plants.

Emissions of PCDD/Fs from many industrial thermal sources have been found to increase significantly as the bag filters or other facilities increase in age, and this phenomenon is normally called the "memory effect". It has been suggested that the memory effect in waste incinerators is caused by POPs being adsorbed and later desorbed. ${ }^{30}$ The memory effect includes the "sorption and desorption memory effect" (which is caused by POPs being absorbed by amorphous materials or adsorbed onto the installation walls or onto deposits of materials in the installation) and the "de novo memory effect" (in which soot deposited in some parts of a system act as a raw material in the de novo synthesis of POPs). ${ }^{31}$ Sorption and desorption may not fully explain the significant increases (by one to 2 orders of magnitude) in the amounts of PBDD/Fs that have been found to form in secondary metal smelting plants over time. Fly ash can be deposited in a facility or in a bag filter 
over time. Our results indicate that the "de novo memory effect" (the thermochemical formation of pollutants mediated by fly ash deposited within a facility) might be the underlying cause (in addition to sorption and desorption) of significant increases in the amounts of $\mathrm{PBDD} / \mathrm{Fs}$ that are formed in secondary metal smelting plants over time.

Congener Patterns of the PBDD/Fs Formed during Fly Ash-Mediated Thermochemical Reactions. The concentrations of the different PBDD/F homologues after experiments at different temperatures had been performed are shown in Figure 2. Very different tetra- to octa-brominated PBDD/F homologue patterns were found after experiments at different temperatures. It can be seen from Figure 2 that the tetrabromodibenzofuran (TeBDF) concentration reached a maximum at $200{ }^{\circ} \mathrm{C}$, the tetrabromodibenzo- $p$-dioxin (TeBDD) concentration reached a maximum at $250{ }^{\circ} \mathrm{C}$, and the TeBDF and TeBDD concentrations decreased as the temperature increased further. The more-brominated PBDD/F homologues were more dominant than the less-brominated $\mathrm{PBDD} / \mathrm{Fs}$ at $350-450{ }^{\circ} \mathrm{C}$. The hepta- and octa-brominated $\mathrm{PBDD} /$ Fs were the dominant homologues, together contributing $56-83 \%$ of the total PBDD/Fs, at $350-450{ }^{\circ} \mathrm{C}$. The change from the less-brominated homologues dominating at lower temperatures to the more-brominated homologues dominating at higher temperatures indicated that bromination reactions may have occurred at higher temperatures. The curves of the TeBDD and TeBDF profiles in Figure 2 were different from the curves of the other congeners, and an explanation for this is given below. The TeBDD and TeBDF activation energies were much lower than the highly brominated congener activation energies, as shown in Table 1 . TeBDD and TeBDF

Table 1. Arrhenius Formulae for the Thermochemical Reactions Involved in the Formation of Polybrominated Dibenzo-p-Dioxins and Dibenzofurans on Secondary Copper Smelter Fly Ash at Between 423 and $723 \mathrm{~K}^{a}$

\begin{tabular}{ll}
\multicolumn{1}{c}{ congener } & arrhenius formula \\
OBDD & $k=2.82 \times 10^{-10} \exp (-39.2 / R T)$ \\
OBDF & $k=5.99 \times 10^{-10} \exp (-38.7 / R T)$ \\
$1234678-\mathrm{HpBDD}$ & $k=6.84 \times 10^{-10} \exp (-44.9 / R T)$ \\
$1234678-\mathrm{HpBDF}$ & $k=6.62 \times 10^{-10} \exp (-44.8 / R T)$ \\
$123478 / 123678-\mathrm{HxBDD}$ & $k=3.21 \times 10^{-10} \exp (-46.9 / R T)$ \\
$123789-\mathrm{HxBDD}$ & $k=6.71 \times 10^{-10} \exp (-50.5 / R T)$ \\
$123478-\mathrm{HxBDF}$ & $k=1.53 \times 10^{-9} \exp (-54.7 / R T)$ \\
$12378-\mathrm{PeBDD}$ & $k=2.41 \times 10^{-11} \exp (-35.2 / R T)$ \\
$23478-\mathrm{PeBDF}$ & $k=2.18 \times 10^{-11} \exp (-34.3 / R T)$ \\
$12378-\mathrm{PeBDF}$ & $k=2.98 \times 10^{-13} \exp (-13.8 / R T)$ \\
$2378-\mathrm{TeBDD}$ & $k=1.51 \times 10^{-11} \exp (-23.1 / R T)$ \\
$2378-\mathrm{TeBDF}$ & $k=4.75 \times 10^{-13} \exp (-8.6 / R T)$
\end{tabular}

${ }^{a} k$ is the rate constant for the formation of the PBDD/F congener of interest during a thermochemical reaction, the first term in parentheses after exp is the activation energy $(E a$ in $\mathrm{kJ} / \mathrm{mol}), R$ is the universal gas constant, and $T$ is the temperature (in $\mathrm{K}$ ). BDD = bromodibenzo- $p$ dioxin, $\mathrm{BDF}=$ bromodibenzofuran, $\mathrm{Te}=$ tetra, $\mathrm{Pe}=$ penta, $\mathrm{Hx}=$ hexa, $\mathrm{Hp}=$ hepta, $\mathrm{O}=$ octa

will therefore be much more easily formed than highly brominated congeners at relatively low temperatures. Increasing the temperature could increase the formation rates of highly brominated congeners and cause TeBDD and TeBDF to be transformed into highly brominated congeners through bromination reactions. The TeBDD and TeBDF concen- trations will therefore slightly decrease when the temperature increases, and the highly brominated congener concentrations will increase at relatively high temperatures.

The PBDD/F congener profiles in the SCu fly ash and in the products of the experiments at different temperatures are shown in Figure 3. Three tetra-brominated congeners $(2,4,6,8$ TeBDF, 2,3,7,8-TeBDF, and 2,3,7,8-TeBDD) made small contributions (6.9\%, 5.8\%, and $6.7 \%$, respectively) to the total PBDD/F concentration in the original SCu fly ash. The $\mathrm{PBDD} / \mathrm{F}$ congener profiles in the products and the SCu fly ash were different. The 2,3,7,8-TeBDD contributions increased until the temperature reached $250{ }^{\circ} \mathrm{C}$, then decreased as the temperature increased further. The 2,4,6,8-TeBDF and 2,3,7,8TeBDF contributions clearly decreased once the temperature became higher than $200{ }^{\circ} \mathrm{C}$. The more-brominated congeners (including 1,2,3,4,6,7,8-heptabromodibenzo-p-dioxin (HpBDD), OBDD, 1,2,3,4,6,7,8-heptabromodibenzofuran (HpBDF), and OBDF) clearly increased as the temperature increased. OBDF was the most abundant congener after the experiment at $450{ }^{\circ} \mathrm{C}$, contributing $31 \%$ of the total PBDD/F concentration. The next most abundant congeners (in decreasing order of contribution) were 1,2,3,4,6,7,8-HpBDF (contributing $29 \%$ of the total), OBDD (12\%), and $1,2,3,4,6,7,8-\mathrm{HpBDD}$ (11\%). These four more-brominated congeners together contributed $83 \%$ of the total $\mathrm{PBDD} / \mathrm{F}$ concentration after the experiment at $450{ }^{\circ} \mathrm{C}$. These results indicated that the formation of highly brominated congeners was favored at relatively high temperatures.

The Arrhenius equation, shown below, describes the dependence of the rate constant $(k)$ of a chemical reaction on the absolute temperature $T$ (in Kelvin). In the equation, $k$ is the rate constant for the formation of $\mathrm{PBDD} / \mathrm{F}$ congeners involved in the thermochemical reactions, $A$ is a preexponential factor, $E_{a}$ is the activation energy, and $R$ is the universal gas constant.

$$
k=\mathrm{Ae}^{-E a /(R T)}
$$

The Arrhenius equation was used to calculate, from the $\mathrm{PBDD} / \mathrm{F}$ congener formation rates, the activation energy and pre-exponential factor for each $\mathrm{PBDD} / \mathrm{F}$ congener during the thermochemical reactions. These calculations were performed with the aim of improving our understanding of the thermochemical behaviors of the PBDD/F congeners. The activation energies and pre-exponential factors that were calculated are shown in Table 1. As can be seen in Figure 3, the formation of the more-brominated $\mathrm{PBDD} / \mathrm{F}$ congeners was found to be very strongly thermodynamically favored at higher temperatures. This would have been why we found that larger amounts of the more-brominated $\mathrm{PBDD} / \mathrm{F}$ congeners were formed in our experiments at higher temperatures. It can be seen from Table 1 that the activation energies of the hexa- and octa-brominated PBDD/F congeners $(38.7-54.7 \mathrm{~kJ} / \mathrm{mol})$ were higher than the activation energies of the tetra- to pentabrominated $\mathrm{PBDD} / \mathrm{F}$ congeners $(8.6-35.2 \mathrm{~kJ} / \mathrm{mol})$. This supported our conclusion that larger amounts of the morebrominated $\mathrm{PBDD} / \mathrm{Fs}$ would be produced at higher temperatures. Ortuno et al. studied the de novo synthesis of PBDD/Fs using model mixtures of active carbon and $\mathrm{CuBr}_{2}{ }^{32}$ They found activation energies for the de novo synthesis of PBDD/ Fs of $78.7-158.4 \mathrm{~kJ} / \mathrm{mol}$, which are higher than the activation energies of $8.6-54.7 \mathrm{~kJ} / \mathrm{mol}$ that we found for the formation of $\mathrm{PBDD} / \mathrm{Fs}$ when $\mathrm{SCu}$ fly ash was used as the matrix for thermochemical reactions. This further supports our conclusion 


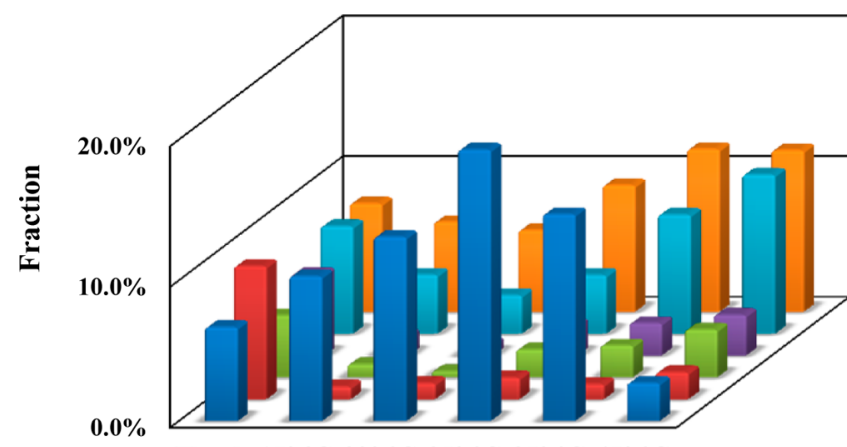

Flyash $150^{\circ} \mathrm{C} 200^{\circ} \mathrm{C} 250{ }^{\circ} \mathrm{C} 350^{\circ} \mathrm{C} 450^{\circ} \mathrm{C}$

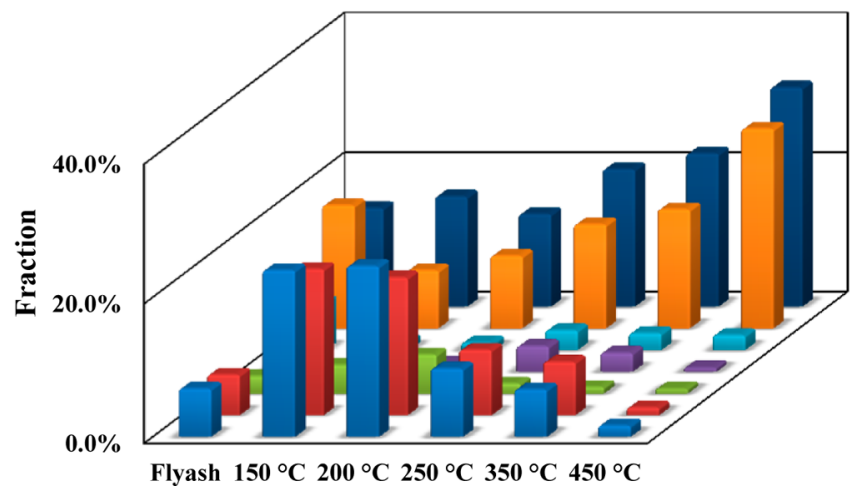

$\square$ 2378-TeBDD

12378-PeBDD

123478/123678-

HxBDD

-123789-HxBDD

1234678-HpBDD

$\because$ OBDD

2468-TeBDF

$₫$ 2378-TeBDF

12378-PeBDF

๑23478-PeBDF

123478-HxBDF

$\square$ 1234678-

HpBDF

- OBDF

Figure 3. (Top) Polybrominated dibenzo- $p$-dioxin and (bottom) polybrominated dibenzofuran congener patterns in the original fly ash and after the thermochemical reaction experiments at different temperatures had been performed (BDD $=$ bromodibenzo- $p$-dioxin, $\mathrm{BDF}=$ bromodibenzofuran, $\mathrm{Te}=$ tetra, $\mathrm{Pe}=$ penta, $\mathrm{Hx}=$ hexa, $\mathrm{Hp}=$ hepta, $\mathrm{O}=$ octa).

that $\mathrm{SCu}$ fly ash is a strong catalyst for the formation of PBDD/ Fs.

The different congener patterns found after different reaction times are shown in Figure 4. The contributions of 2,3,7,8TeBDD, 2,4,6,8-TeBDF, and 2,3,7,8-TeBDF to the total $\mathrm{PBDD} / \mathrm{F}$ concentration decreased as the reaction time increased. The contributions of the more-brominated congeners, including 1,2,3,4,6,7,8-HpBDD, OBDD, 1,2,3,4,6,7,8$\mathrm{HpBDF}$, and $\mathrm{OBDF}$, clearly increased as the reaction time increased. These trends indicated that the 2,3,7,8-TeBDD, 2,4,6,8-TeBDF, and 2,3,7,8-TeBDF formation reactions tended to reach equilibrium more quickly than the $1,2,3,4,6,7,8$ HpBDD, OBDD, 1,2,3,4,6,7,8-HpBDF, and OBDF formation reactions. A longer reaction time would therefore favor the formation of the more-brominated congeners.

Formation of PBDEs during Fly Ash-Mediated Thermochemical Reactions and the Relationship between the Formation of PBDEs and the Formation of PBDD/Fs. Extensive use of brominated flame retardants, especially PBDEs, in the past means that more brominated precursors of $\mathrm{PBDD} / \mathrm{Fs}$ are now present in the raw materials used in secondary metal smelting than would have previously been the case. ${ }^{33}$ The likelihood of PBDD/Fs forming during industrial thermal processes is therefore higher than it would previously have been. ${ }^{34-36}$ High $\mathrm{PBDD} / \mathrm{F}$ yields have been found when PBDEs have been thermally treated. ${ }^{33,37,38} \mathrm{We}$ therefore measured the PBDE concentrations in the products of the experiments and in the SCu fly ash to allow the relationship between the formation of PBDEs and PBDD/Fs to be investigated.

It is widely accepted that PBDEs are important precursors of PBDD/Fs formed during industrial thermal processes. ${ }^{19,35,39}$ The PBDE concentrations in the original fly ash and in the products of the experiments are presented in Figure 5. The $\mathrm{PBDE}$ concentration in the original fly ash was $0.08 \mu \mathrm{g} / \mathrm{g}$. It can be seen from Figure 5 that the PBDE concentration increased significantly after the SCu fly ash had been thermally treated. The PBDE concentrations were 3.4-5.3 $\mu \mathrm{g} / \mathrm{g}$ after $30 \mathrm{~min}$ experiments at $250-450{ }^{\circ} \mathrm{C}$ had been performed. The highest PBDE concentration $(5.3 \mu \mathrm{g} / \mathrm{g}$, more than 67 times higher than the PBDE concentration in the original fly ash) was found after the $\mathrm{SCu}$ fly ash had been heated to $350{ }^{\circ} \mathrm{C}$ for $30 \mathrm{~min}$. The considerably higher PBDE concentrations after the fly ash had been heated than in the original fly ash indicated that large quantities of PBDEs were formed on the SCu fly ash through thermochemical reactions. It has been found that de novo synthesis of unintentionally produced POPs, including PCDD/ Fs, polychlorinated naphthalenes, and other halogenated organic compounds, from carbon sources can be catalyzed by compounds of copper or other metals. ${ }^{20,40,41}$ It has also been suggested that de novo synthesis of PBDEs from organic residues (acting as carbon sources) produced by plastics and cables in the raw materials used in $\mathrm{SCu}$ processes can occur, ${ }^{42}$ and that this is catalyzed by copper compounds.

The $\mathrm{PBDE}$ to $\mathrm{PBDD} / \mathrm{F}$ concentration ratios for the experiments performed under different conditions are shown in Figure 5. It can be seen that the PBDE concentrations were 41-328 times higher than the PBDD/F concentrations. Vetter et al. found that about $0.5 \%$ of the decabromodiphenyl ether present could be transformed into $\mathrm{PBDD} / \mathrm{Fs}$ when complex matrices containing decabromodiphenyl ether were heated. ${ }^{38}$ The PBDE to PBDD/F ratios found by Vetter et al. ${ }^{38}$ were similar to the PBDE to PBDD/F ratios for our experiments. Altarawneh et al. performed a detailed mechanistic and kinetic study of the formation of $\mathrm{PBDD} / \mathrm{Fs}$ from PBDEs, and their theoretical calculations indicated that the loss of a $\mathrm{Br}$ or $\mathrm{H}$ atom 


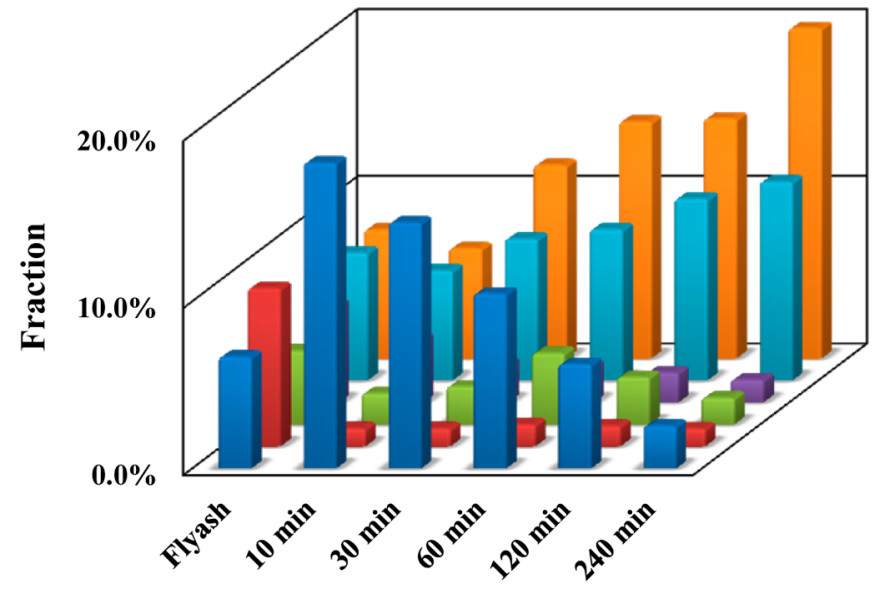

$\square$ 2378-TeBDD

$\square$ 12378-PeBDD

$\square$ 123478/123678-

HxBDD

$\square$ 123789-HxBDD

1234678-HpBDD

$\varpi$ OBDD

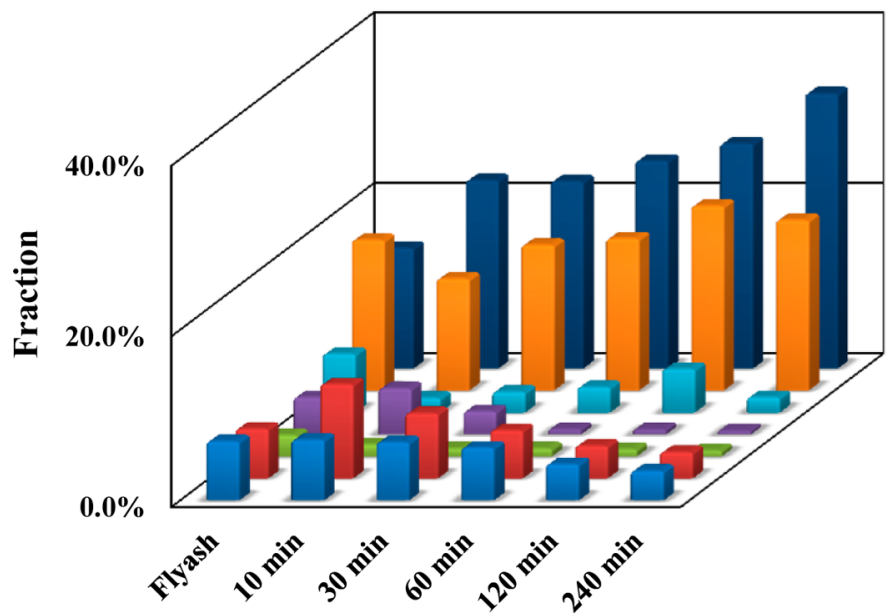

2468-TeBDF

2378-TeBDF

$\square$ 12378-PeBDF

口23478-PeBDF

123478-HxBDF

1234678-HpBDF

๑ OBDF

Figure 4. (Top) Polybrominated dibenzo- $p$-dioxin and (bottom) polybrominated dibenzofuran congener patterns in the original fly ash and after the thermochemical reaction experiments with different reaction times had been performed $(\mathrm{BDD}=$ bromodibenzo- $p$-dioxin, $\mathrm{BDF}=$ bromodibenzofuran, $\mathrm{Te}=$ tetra, $\mathrm{Pe}=$ penta, $\mathrm{Hx}=$ hexa, $\mathrm{Hp}=$ hepta, $\mathrm{O}=$ octa).

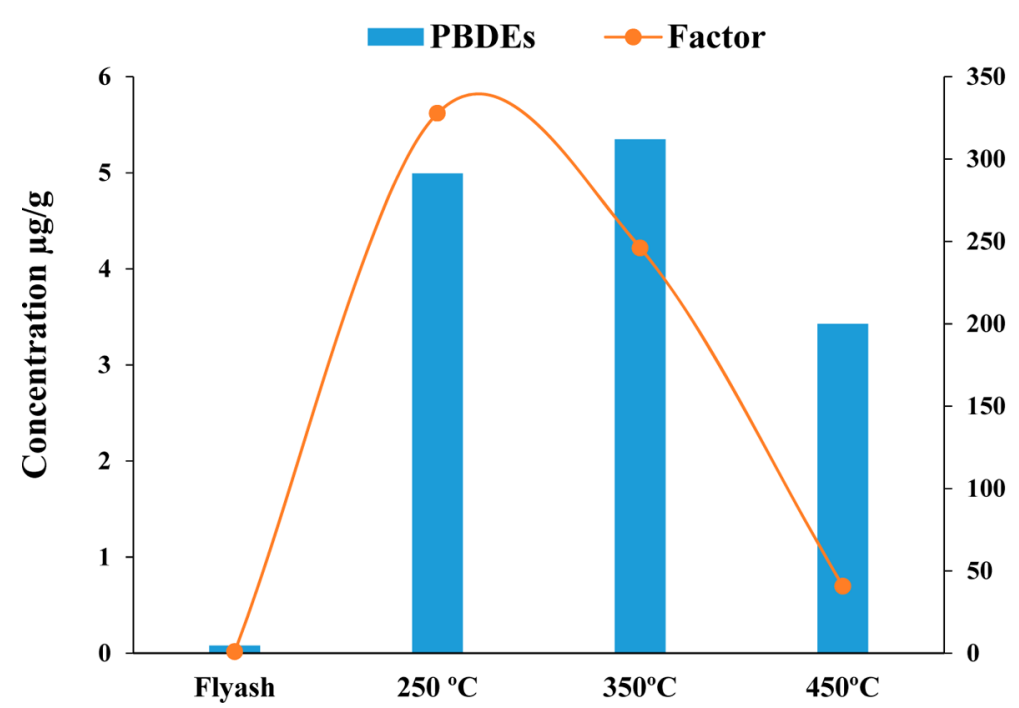

Figure 5. Polybrominated diphenyl ether concentrations (bars and left $y$-axis) after thermochemical reaction experiments at different temperatures had been performed, and the polybrominated diphenyl ether to polybrominated dibenzo- $p$-dioxin and dibenzofuran concentration ratios (factor; points and right $y$-axis).

from the ortho position of a PBDE then a ring-closure reaction is the most accessible PBDF-production pathway with modest reaction barriers. ${ }^{39}$ Weber and Kuch found that PBDD/Fs can be formed from PBDEs through the simple intramolecular elimination of $\mathrm{HBr}^{19}$ The large amounts of PBDEs formed during fly ash-mediated thermochemical reactions could 
therefore provide abundant brominated $\mathrm{PBDD} / \mathrm{F}$ precursors, allowing $\mathrm{PBDD} / \mathrm{Fs}$ to be formed on $\mathrm{SCu}$ fly ash through thermochemical reactions. Weber and Kuch summarized the possible pathways for PBDD/Fs to be formed from brominated flame retardants. ${ }^{19}$ The results of our study on the formation of $\mathrm{PBDD} / \mathrm{Fs}$ during $\mathrm{SCu}$ processes supported the mechanisms Weber and Kuch suggested for the formation of PBDD/Fs from PBDEs. ${ }^{19}$ The possible pathways through which PBDD/ Fs can be formed from PBDEs during thermochemical processes were determined from our results and the results of the study performed by Weber and Kuch, ${ }^{19}$ and the pathways are shown schematically in SI Figure S3.

Environmental Implications and Strategies for Decreasing PBDD/Fs Emissions. Fly ash is normally recycled by adding it to the raw materials used in a smelter or simply by thermally treating it during the smelting process. ${ }^{43}$ The significant increases in $\mathrm{PBDD} / \mathrm{F}$ concentrations caused by fly ash-mediated thermochemical reactions mean that fly ash must be disposed of safely rather than simply recycled by adding it to the raw materials or by thermally treating it in SCu plants and other metallurgical plants.

Air pollution control devices that are used to decrease particle emissions from industrial facilities efficiently decrease emissions of PCDD/Fs and similar compounds to the atmosphere because the devices remove particles containing the pollutants. ${ }^{44,45}$ APCDs are normally operated below $200^{\circ} \mathrm{C}$ because $\mathrm{PCDD} / \mathrm{Fs}$ and similar compounds are not generally formed below $200{ }^{\circ} \mathrm{C}$. However, PBDD/Fs clearly formed on fly ash at below $200{ }^{\circ} \mathrm{C}$ in our study, suggesting that PBDD/Fs could form in APCDs in industrial plants, particularly in secondary nonferrous smelting plants, even when the APCDs are operated at temperatures below $200{ }^{\circ} \mathrm{C}$.

The promotion of $\mathrm{PBDD} / \mathrm{F}$ formation by fly ash allows us to suggest a novel way of controlling the formation and emission of unintentionally produced POPs. Fly ash deposited in a smelting facility and APCDs could contribute to significant increases in the amounts of $\mathrm{PBDD} / \mathrm{Fs}$ formed during $\mathrm{SCu}$ processes. Therefore, periodically removing fly ash deposited in a smelting facility and APCDs can directly and effectively decrease the amounts of $\mathrm{PBDD} / \mathrm{Fs}$ formed during industrial processes.

The intentional production of PBDEs for use as brominated flame retardants has been banned because PBDEs have been added to Annex A of the Stockholm Convention. ${ }^{46}$ POPs that can be unintentionally produced during industrial thermal processes (e.g., PCDD/Fs, polychlorinated biphenyls, polychlorinated naphthalenes, hexachlorobenzene, and pentachlorobenzene) are included in Annex $\mathrm{C}$ of the Stockholm Convention, which requires measures aimed at decreasing unintentional emissions of these compounds to be taken. PBDE emissions from some industrial thermal processes have been explained by the incomplete destruction of PBDEs (present as impurities) in the raw materials. ${ }^{47,48}$ No direct experimental evidence is available to support the reformation of PBDEs during industrial thermal processes, especially during $\mathrm{SCu}$ processes. Our results indicate that significant amounts of PBDEs can be formed through fly ash-mediated thermochemical reactions, suggesting that $\mathrm{SCu}$ processes could be important sources of PBDE emissions. This indicates that unintentional emissions of PBDEs must be considered (in addition to the production and release of PBDEs used as brominated flame retardants) when compiling a PBDE inventory.

\section{ASSOCIATED CONTENT}

Supporting Information

The Supporting Information is available free of charge on the ACS Publications website at DOI: 10.1021/acs.est.6b02119.

Tables S1-S5 and Figures S1-S3 (PDF)

\section{AUTHOR INFORMATION}

\section{Corresponding Author}

*Phone: +86 106284 9356; fax: +86 106284 9355; e-mail: grliu@rcees.ac.cn.

\section{Notes}

The authors declare no competing financial interest.

\section{ACKNOWLEDGMENTS}

We gratefully acknowledge support from the National 973 program (2015CB453100), the National Natural Science Foundation of China (21477147), the Strategic Priority Research Program of the Chinese Academy of Sciences (XDB14020102), and the Youth Innovation Promotion Association Chinese Academy of Sciences (2016038).

\section{REFERENCES}

(1) Altarawneh, M.; Dlugogorski, B. Z.; Kennedy, E. M.; Mackie, J. C. Mechanisms for formation, chlorination, dechlorination and destruction of polychlorinated dibenzo-p-dioxins and dibenzofurans (PCDD/ Fs). Prog. Energy Combust. Sci. 2009, 35 (3), 245-274.

(2) Liu, G.; Jiang, X.; Wang, M.; Dong, S.; Zheng, M. Comparison of $\mathrm{PCDD} / \mathrm{F}$ levels and profiles in fly ash samples from multiple industrial thermal sources. Chemosphere 2015, 133, 68-74.

(3) Addink, R; Olie, K. Mechanisms of formation and destruction of polychlorinated dibenzo-p-dioxins and dibenzofurans in heterogeneous systems. Environ. Sci. Technol. 1995, 29 (6), 1425-1435.

(4) Fujimori, T.; Takaoka, M.; Takeda, N. Influence of $\mathrm{Cu}, \mathrm{Fe}, \mathrm{Pb}$, and $\mathrm{Zn}$ Chlorides and Oxides on Formation of Chlorinated Aromatic Compounds in MSWI Fly Ash. Environ. Sci. Technol. 2009, 43 (21), 8053-8059.

(5) Hinton, W. S.; Lane, A. M. Effect of zinc, copper, and sodium on formation of polychlorinated dioxins on MSW incinerator fly ash. Chemosphere 1992, 25 (6), 811-819.

(6) Takaoka, M.; Shiono, A.; Nishimura, K.; Yamamoto, T.; Uruga, T.; Takeda, N.; Tanaka, T.; Oshita, K.; Matsumoto, T.; Harada, H. Dynamic change of copper in fly ash during de novo synthesis of dioxins. Environ. Sci. Technol. 2005, 39 (15), 5878-5884.

(7) Nganai, S.; Lomnicki, S. M.; Dellinger, B. Formation of PCDD/ Fs from the copper oxide-mediated pyrolysis and oxidation of 1,2dichlorobenzene. Environ. Sci. Technol. 2010, 45 (3), 1034-1040.

(8) Fujimori, T.; Tanino, Y.; Takaoka, M. Coexistence of $\mathrm{Cu}, \mathrm{Fe}, \mathrm{Pb}$, and $\mathrm{Zn}$ oxides and chlorides as a determinant of dhlorinated aromatics generation in municipal solid waste incinerator fly ash. Environ. Sci. Technol. 2013, 48 (1), 85-92.

(9) Ryu, J.-Y.; Mulholland, J. A.; Chu, B. Chlorination of dibenzofuran and dibenzo-p-dioxin vapor by copper (II) chloride. Chemosphere 2003, 51 (10), 1031-1039.

(10) Chin, Y. T.; Lin, C.; Chang-Chien, G. P.; Wang, Y. M. PCDD/ Fs formation catalyzed by the copper chloride in the fly ash. J. Environ. Sci. Health, Part A: Toxic/Hazard. Subst. Environ. Eng. 2011, 46 (5), 465-470.

(11) Olie, K.; Addink, R.; Schoonenboom, M. Metals as catalysts during the formation and decomposition of chlorinated dioxins and furans in incineration processes. J. Air Waste Manage. Assoc. 1998, 48 (2), 101-105.

(12) Stieglitz, L.; Zwick, G.; Beck, J.; Bautz, H.; Roth, W. Carbonaceous particles in fly ash -a source for the de-novo-synthesis of organochlorocompounds. Chemosphere 1989, 19 (1-6), 283-290. 
(13) Behnisch, P. A.; Hosoe, K.; Sakai, S.-i. Brominated dioxin-like compounds: in vitro assessment in comparison to classical dioxin-like compounds and other polyaromatic compounds. Environ. Int. 2003, 29 (6), 861-877.

(14) Shaw, S. D.; Berger, M. L.; Harris, J. H.; Yun, S. H.; Wu, Q.; Liao, C.; Blum, A.; Stefani, A.; Kannan, K. Persistent organic pollutants including polychlorinated and polybrominated dibenzo-p-dioxins and dibenzofurans in firefighters from Northern California. Chemosphere 2013, 91 (10), 1386-1394.

(15) Venkatesan, A. K.; Halden, R. U. Contribution of polybrominated dibenzo-p-dioxins and dibenzofurans ( $\mathrm{PBDD} / \mathrm{Fs}$ ) to the toxic equivalency of dioxin-like compounds in archived biosolids from the US EPA's 2001 National Sewage Sludge Survey. Environ. Sci. Technol. 2014, 48 (18), 10843-10849.

(16) Du, B.; Zheng, M.; Tian, H.; Liu, A.; Huang, Y.; Li, L.; Ba, T.; Li, N.; Ren, Y.; Li, Y.; Dong, S.; Su, G. Occurrence and characteristics of polybrominated dibenzo-p-dioxins and dibenzofurans in stack gas emissions from industrial thermal processes. Chemosphere 2010, 80 (10), 1227-1233.

(17) Wang, M.; Liu, G.; Jiang, X.; Li, S.; Liu, W.; Zheng, M. Formation and emission of brominated dioxins and furans during secondary aluminum smelting processes. Chemosphere 2016, 146, 6067.

(18) Cains, P. W.; McCausland, L. J.; Fernandes, A. R.; Dyke, P. Polychlorinated dibenzo-p-dioxins and dibenzofurans formation in incineration: effects of fly ash and carbon source. Environ. Sci. Technol. 1997, 31 (3), 776-785.

(19) Weber, R.; Kuch, B. Relevance of BFRs and thermal conditions on the formation pathways of brominated and brominatedchlorinated dibenzodioxins and dibenzofurans. Environ. Int. 2003, 29 (6), 699-710.

(20) Ortuno, N.; Conesa, J. A.; Molto, J.; Font, R. De novo synthesis of brominated dioxins and furans. Environ. Sci. Technol. 2014, 48 (14), 7959-7965.

(21) Jiang, X.; Liu, G.; Wang, M.; Zheng, M. Fly ash-mediated formation of polychlorinated naphthalenes during secondary copper smelting and mechanistic aspects. Chemosphere 2015, 119, 10911098.

(22) Wang, M.; Liu, G.; Jiang, X.; Xiao, K.; Zheng, M. Formation and potential mechanisms of polychlorinated dibenzo-p-dioxins and dibenzofurans on fly ash from a secondary copper smelting process. Environ. Sci. Pollut. Res. 2015, 22 (11), 8747-8755.

(23) Li, S.; Liu, W.; Liu, G.; Wang, M.; Li, C.; Zheng, M. Atmospheric emission of polybrominated dibenzo-p-dioxins and dibenzofurans from converter steelmaking processes. Aerosol Air Qual. Res. 2015, 15, 1118-1124.

(24) Tuppurainen, K.; Halonen, I.; Ruokojärvi, P.; Tarhanen, J.; Ruuskanen, J. Formation of PCDDs and PCDFs in municipal waste incineration and its inhibition mechanisms: A review. Chemosphere 1998, 36 (7), 1493-1511.

(25) Huang, H.; Buekens, A. On the mechanisms of dioxin formation in combustion processes. Chemosphere 1995, 31 (9), 4099-4117.

(26) Xhrouet, C.; Pirard, C.; De Pauw, E. De novo synthesis of polychlorinated dibenzo-p-dioxins and dibenzofurans on fly ash from a sintering process. Environ. Sci. Technol. 2001, 35 (8), 1616-1623.

(27) Birnbaum, L. S.; Staskal, D. F.; Diliberto, J. J. Health effects of polybrominated dibenzo-p-dioxins (PBDDs) and dibenzofurans (PBDFs). Environ. Int. 2003, 29 (6), 855-860.

(28) Loganathan, B. G.; Kannan, K.; Watanabe, I.; Kawano, M.; Irvine, K.; Kumar, S.; Sikka, H. C. Isomer-specific determination and toxic evaluation of polychlorinated biphenyls, polychlorinated/ brominated dibenzo-p-dioxins and dibenzofurans, polybrominated biphenyl ethers, and extractable organic halogen in carp from the Buffalo River, New York. Environ. Sci. Technol. 1995, 29 (7), 18321838.

(29) Ma, J.; Addink, R.; Yun, S.; Cheng, J.; Wang, W.; Kannan, K. Polybrominated dibenzo-p-dioxins/dibenzofurans and polybrominated diphenyl ethers in soil, vegetation, workshop-floor dust, and electronic shredder residue from an electronic waste recycling facility and in soils from a chemical industrial complex in eastern China. Environ. Sci. Technol. 2009, 43 (19), 7350-7356.

(30) Li, H.-W.; Wang, L.-C.; Chen, C.-C.; Yang, X.-Y.; Chang-Chien, G.-P.; Wu, E. M.-Y. Influence of memory effect caused by aged bag filters on the stack PCDD/F emissions. J. Hazard. Mater. 2011, 185 $(2-3), 1148-1155$

(31) Weber, R.; Sakurai, T.; Ueno, S.; Nishino, J. Correlation of $\mathrm{PCDD} / \mathrm{PCDF}$ and CO values in a MSW incinerator - indication of memory effects in the high temperature/cooling section. Chemosphere 2002, 49 (2), 127-134.

(32) Ortuño, N.; Conesa, J. A.; Moltó, J.; Font, R. De novo synthesis of brominated dioxins and furans. Environ. Sci. Technol. 2014, 48 (14), 7959-7965.

(33) Zhang, M.; Buekens, A.; Li, X. Brominated flame retardants and the formation of dioxins and furans in fires and combustion. J. Hazard. Mater. 2016, 304, 26-39.

(34) D'Silva, K.; Fernandes, A.; Rose, M. Brominated organic micropollutants-igniting the flame retardant issue. Crit. Rev. Environ. Sci. Technol. 2004, 34 (2), 141-207.

(35) Sindiku, O.; Babayemi, J.; Osibanjo, O.; Schlummer, M.; Schluep, M.; Watson, A.; Weber, R. Polybrominated diphenyl ethers listed as Stockholm Convention POPs, other brominated flame retardants and heavy metals in e-waste polymers in Nigeria. Environ. Sci. Pollut. Res. 2015, 22, 1-13.

(36) Ortuno, N.; Lundstedt, S.; Lundin, L. Emissions of PBDD/Fs, $\mathrm{PCDD} / \mathrm{Fs}$ and PBDEs from flame-retarded high-impact polystyrene under thermal stress. Chemosphere 2015, 123, 64-70.

(37) Ren, M.; Peng, P. a.; Cai, Y.; Chen, D.; Zhou, L.; Chen, P.; Hu, J. PBDD/F impurities in some commercial deca-BDE. Environ. Pollut. 2011, 159 (5), 1375-1380.

(38) Vetter, W.; Bendig, P.; Blumenstein, M.; Hägele, F.; Behnisch, P. A.; Brouwer, A. Formation of polybrominated dibenzofurans (PBDFs) after heating of a salmon sample spiked with decabromodiphenyl ether (BDE-209). Environ. Sci. Pollut. Res. 2015, 22 (19), 14530-14536.

(39) Altarawneh, M.; Dlugogorski, B. Z. A mechanistic and kinetic study on the formation of PBDD/Fs from PBDEs. Environ. Sci. Technol. 2013, 47 (10), 5118-5127.

(40) Weber, R.; Iino, F.; Imagawa, T.; Takeuchi, M.; Sakurai, T.; Sadakata, M. Formation of PCDF, PCDD, PCB, and PCN in de novo synthesis from $\mathrm{PAH}$ : Mechanistic aspects and correlation to fluidized bed incinerators. Chemosphere 2001, 44 (6), 1429-1438.

(41) Iino, F.; Imagawa, T.; Takeuchi, M.; Sadakata, M. De novo synthesis mechanism of polychlorinated dibenzofurans from polycyclic aromatic hydrocarbons and the characteristic isomers of polychlorinated naphthalenes. Environ. Sci. Technol. 1999, 33 (7), 1038-1043.

(42) Hu, J. C.; Zheng, M. H.; Liu, W. B.; Li, C. L.; Nie, Z. Q.; Liu, G. R; Xiao, K.; Dong, S. J. Occupational exposure to polychlorinated dibenzo-p-dioxins and dibenzofurans, dioxin-like polychlorinated biphenyls, and polychlorinated naphthalenes in workplaces of secondary nonferrous metallurgical facilities in China. Environ. Sci. Technol. 2013, 47 (14), 7773-7779.

(43) Hu, J.; Zheng, M.; Nie, Z.; Liu, W.; Liu, G.; Zhang, B.; Xiao, K. Polychlorinated dibenzo-p-dioxin and dibenzofuran and polychlorinated biphenyl emissions from different smelting stages in secondary copper metallurgy. Chemosphere 2013, 90 (1), 89-94.

(44) McKay, G. Dioxin characterisation, formation and minimisation during municipal solid waste (MSW) incineration: review. Chem. Eng. J. 2002, 86 (3), 343-368.

(45) Kulkarni, P. S.; Crespo, J. G.; Afonso, C. A. Dioxins sources and current remediation technologies-a review. Environ. Int. 2008, 34 (1), 139-153.

(46) UNEP, Stockholm Convention on Persistent Organic Pollutants. 2015. http://chm.pops.int/TheConvention/ThePOPs/ TheNewPOPs/tabid/2511/Default.aspx.

(47) Wang, L.-C.; Hsi, H.-C.; Wang, Y.-F.; Lin, S.-L.; Chang-Chien, G.-P. Distribution of polybrominated diphenyl ethers (PBDEs) and polybrominated dibenzo-p-dioxins and dibenzofurans $(\mathrm{PBDD} / \mathrm{Fs})$ in municipal solid waste incinerators. Environ. Pollut. 2010, 158 (5), $1595-1602$ 
(48) Sakai, S.-i.; Watanabe, J.; Honda, Y.; Takatsuki, H.; Aoki, I.; Futamatsu, M.; Shiozaki, K. Combustion of brominated flame retardants and behavior of its byproducts. Chemosphere 2001, 42 (5-7), 519-531. 